\title{
Surto de intoxicação por monensina em avestruzes e equinos no sul do Brasil ${ }^{1}$
}

\author{
Saulo P. Pavarini ${ }^{2}$, Flademir Wouters ${ }^{2}$, Paulo M. Bandarra ${ }^{2}$, Felipe S. Souza ${ }^{2}$, \\ André G.C. Dalto ${ }^{2}$, Danilo C. Gomes ${ }^{2}$, Cláudio E.F. Cruz ${ }^{2}$ e David Driemeier ${ }^{2 *}$
}

\begin{abstract}
Pavarini S.P., Wouters F., Bandarra P.M., Souza F.S., Dalto A.G.C., Gomes D.C., Cruz C.E.F. \& Driemeier D. 2011. [Outbreak of monensin poisoning in ostriches and horses in southern Brazil.] Surto de intoxicação por monensina em avestruzes e equinos no Sul do Brasil. Pesquisa Veterinária Brasileira 31(10):844-850. Setor de Patologia Veterinária, Faculdade de Veterinária, Universidade Federal do Rio Grande do Sul, Av. Bento Gonçalves 9090, Porto Alegre, RS 91540-000, Brazil. E-mail: davetpat@ufrgs.br

An outbreak of monensin poisoning affected ostriches and horses from a farm in Rio Grande do Sul. Eight days before the onset of clinical signs, a commercial cattle concentrate containing monensin $(177 \mathrm{ppm})$ was introduced in the diet of the animals. Three horses showed difficulty moving, cramping, sweating and permanent recumbency, and death within 48 hours. Three ostriches showed sternal permanent recumbency or sluggish and reluctance to move. Two ostriches died 15 and 30 days after the onset of signs. Gross changes in the horses included multifocal myocardial pallor, endocardial and epicardial hemorrhages mainly around the coronary vessels, and bilateral yellowish white foci in skeletal muscles. Histological lesions were necrotic myopathy and cardiomyopathy. At necropsy of ostriches, skeletal muscles were diffusely pale with multiple small white spots, which corresponded to polyphasic segmental necrosis and regenerative changes.
\end{abstract}

INDEX TERMS: Poisoning, ionophore antibiotics, monensin, ostrich, horse, muscle necrosis.

RESUMO.- Descreve-se um surto de intoxicação por monensina em avestruzes e equinos em uma propriedade no Rio Grande do Sul. Oito dias antes do aparecimento dos primeiros sinais clínicos, uma ração comercial formulada para bovinos, cuja composição incluía monensina (177ppm), foi introduzida na dieta dos animais. Três equinos manifestaram dificuldade de movimentação, cólica, sudorese e decúbito permanente; dois morreram em 48 horas após o inicio dos sinais. Três avestruzes adoeceram, dois apresentaram decúbito esternal permanente, o outro estava apático e relutante ao movimento. Dois avestruzes morreram 15 e 30 dias após o início dos sinais. Nas necropsias dos equinos, observou-se miocárdio com palidez multifocal, hemorragia no endocárdio e no epicárdio (principalmente ao redor dos vasos coronarianos) e musculatura esquelética com áreas branco-amareladas

\footnotetext{
${ }^{1}$ Recebido em 12 de agosto de 2011.

Aceito para publicação em 26 de agosto de 2011.

${ }^{2}$ Setor de Patologia Veterinária, Faculdade de Veterinária, Universidade Federal do Rio Grande do Sul (UFRGS), Av. Bento Gonçalves 9090, Porto Alegre, RS 91540-000, Brasil. *Autor para correspondência: davetpat@ufrgs.br
}

bilaterais e focalmente extensas. Essas alterações corresponderam histologicamente, à miopatia e cardiomiopatia necróticas. Nos avestruzes, músculos esqueléticos difusamente pálidos e com múltiplos pequenos pontos brancos corresponderam à necrose segmentar polifásica, com alterações necróticas e regenerativas.

TERMOS DE INDEXAÇÃO: Intoxicação, antibiótico ionóforo, monensina, avestruz, equino, necrose muscular.

\section{INTRODUÇÃo}

Monensina é um antibiótico ionóforo (AI) produzido pelo fungo Streptomyces cinnamonensis. Os AIs são utilizados, em veterinária, como coccidiostáticos, antimicrobianos, promotores de crescimento, agentes preventivos de timpanismo, edema pulmonar agudo e enfisema em bovinos, além de reguladores do $\mathrm{pH}$ ruminal. Monensina, lasalocida, narasina e salinomicina são os AIs mais utilizados, especialmente em criações de aves, suínos e bovinos. Essas substâncias formam complexos lipídicos solúveis, com cátions mono e divalentes $\left(\mathrm{K}^{+}, \mathrm{Ca}^{++}, \mathrm{Mg}^{++}\right)$, os quais alteram a permeabilidade das membranas, facilitam o fluxo de íons 
para o interior das células e comprometem o equilíbrio osmótico e eletrolítico que causam a degeneração de micro-organismos. 0 mesmo efeito ocorre nas membranas celulares de animais que ingerem doses tóxicas de AI (Barros 2007, Nogueira et al. 2009).

Embora seguros, quando usados para as espécies-alvo e nas doses recomendadas, a intoxicação por monensina tem sido descrita em equinos (Bezerra et al. 1999), bovinos (Schweitzer et al. 1984), ovinos (França et al. 2009), suínos (Miskimins \& Neiger 1996), cães (Wilson 1990), bubalinos (Rozza et al. 2006), galinhas (Hanrahan et al. 1981) e avestruzes (Gregory et al 1992, Baird et al. 1997, Dedoussi et al. 2007), entre outras espécies animais. A intoxicação ocorre devido à ingestão excessiva de AI que decorre de erro na mistura do aditivo à ração, ou no cálculo das dosagens, utilização em espécies mais suscetíveis, uso em associação com medicamentos (tiamulina, cloranfenicol, eritromicina) que potencializam seus efeitos e uso de cama de aves tratadas com AI na dieta de ruminantes. As lesões associadas à intoxicação são caracterizadas, principalmente, por miopatia e cardiomiopatia degenerativas (Barros 2007, Nogueira et al. 2009). A intoxicação espontânea por monensina em avestruzes não havia sido descrita no Brasil e dados sobre a intoxicação em equinos no Brasil são escassos (Bezerra et al. 1999). Esse trabalho descreve os achados epidemiológicos, bioquímicos e clínico-patológicos de um surto de intoxicação por monensina que afetou avestruzes e equinos, em uma mesma propriedade no Rio Grande do Sul.

\section{MATERIAL E MÉTODOS}

Dados epidemiológicos e sinais clínicos da enfermidade foram obtidos em visitas à propriedade. Amostras de sangue dos animais afetados (Equinos 1, 2 e 3, Avestruzes 1, 2 e 3) foram coletadas em tubo sem anti-coagulante para subsequente obtenção de amostras de soro submetidas a testes bioquímicos para mensuração da atividade sérica das enzimas creatina fosfoquinase (CK), aspartato aminotransferase (AST) e desidrogenase láctica (LDH), esta apenas em amostras dos avestruzes. Foram necropsiados dois equinos (Equinos 1 e 2) e dois avestruzes (Avestruzes1 e 2). Amostras de tecidos e órgãos foram coletadas durante a necropsia dos animais e fixadas em solução tamponada de formalina a $10 \%$. Foram coletados, separadamente, fragmentos de diversos grupos musculares dos equinos e dos avestruzes. Posteriormente, as amostras foram clivadas, desidratadas em concentrações crescentes de álcool etílico, diafanizadas em xilol e incluídas em parafina. Cortes de 3-4 $\mu \mathrm{m}$ foram corados por hematoxilina e eosina (HE). Cortes de saco aéreo e pulmões dos avestruzes foram corados com Prata Metenamina de Grocott (PMG) e fragmentos de músculos dos avestruzes, nas quais se observaram lesões caracterizadas por fibrose na coloração de HE, foram corados pela técnica tricrômico de Masson (TM). Amostras da ração consumida pelos animais foram coletadas para dosagem de monensina através de cromatografia líquida de alto desempenho (HPLC). Fragmentos dos sacos aéreos do Avestruz 2 foram coletados para cultivo bacteriano em meio aeróbio.

\section{RESULTADOS}

As intoxicações afetaram três equinos e três avestruzes de uma propriedade rural do Município de Eldorado do Sul/
RS, em março de 2010. Oito dias antes do aparecimento dos primeiros sinais clínicos, uma ração comercial formulada para bovinos, cuja composição incluía monensina, foi introduzida na dieta dos animais. A dosagem de 177 ppm (partes por milhão) de monensina por quilo foi detectada na ração utilizada. Cada um dos sete equinos consumia quatro quilos da ração por dia, dividida em duas partes; enquanto os três avestruzes consumiam cerca de oito quilos de ração ao dia. Suínos e ovelhas da propriedade também consumiam essa ração.

Os primeiros animais que adoeceram foram os equinos. Equino 1 (égua Crioula, 10 anos) foi encontrado no potreiro sem conseguir se movimentar, em decúbito esternal e sudorese intensa. No mesmo dia, o Equino 2 (égua Crioula, 7 anos) foi encontrado com manifestações clínicas compatíveis com cólica; estava inquieto, deitava e rolava no chão com frequência e mordia o flanco. Os animais foram conduzidos para um local coberto e foram tratados com fluidoterapia parenteral. 0 Equino 1 morreu, aproximadamente, 12 horas após ser encontrado no potreiro. 0 Equino 2, no dia seguinte, mantinha-se apenas em decúbito esternal e com intensa sudorese (Fig.1). Após 48 horas do início dos sinais clínicos, o equino 2 morreu. 0 Equino 3 (cavalo, raça Crioula, 22 anos) apresentou relutância em se movimentar, hesitação em mudar de direção com tendência a tropeços, membros pélvicos rígidos e lateralmente afastados, além de andar cambaleante. Os sinais clínicos perduraram três dias e o animal não morreu. A análise bioquímica do soro dos três equinos (coletados no primeiro dia de doença clínica) revelou valores superiores aos normais para a espécie na dosagem de CK e AST (valores apresentados no Quadro 1).

Um dia após o início dos sinais clínicos nos equinos, o Avestruz 1 (fêmea adulta) e Avestruz 2 (macho adulto) foram encontrados em decúbito esternal permanente no curral e o Avestruz 3 (fêmea adulta) estava apático e relutante ao movimento. No mesmo dia, foram coletadas amostras de sangue das três aves e, na análise bioquímica do soro, a atividade das enzimas CK, AST e LH estavam aumentadas (valores apresentados no Quadro 2). Os animais apresentavam diarreia e inapetência e, após 3 dias, o

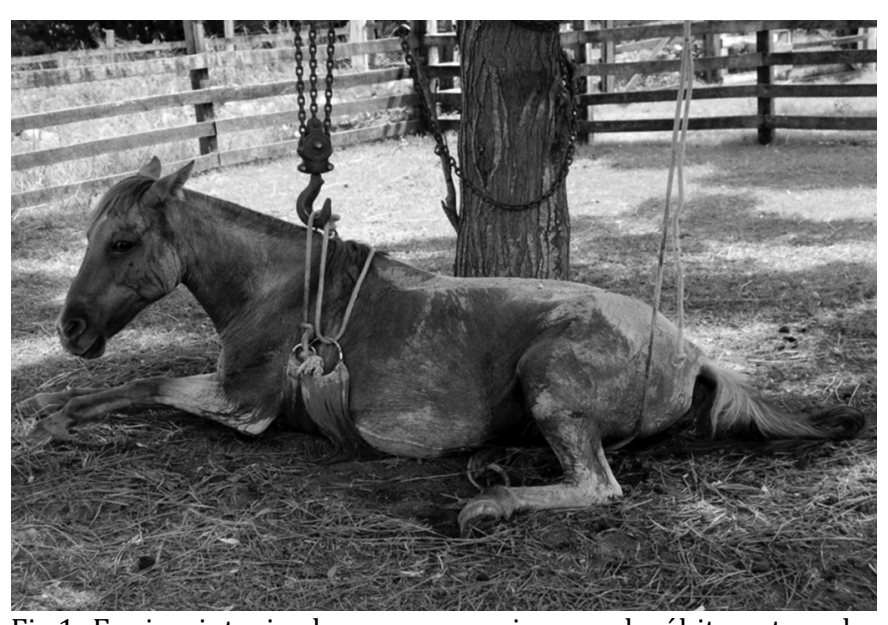

Fig.1. Equino intoxicado por monensina em decúbito esternal e com intensa sudorese. 
Quadro 1. Resultados da quantificação da atividade das enzimas CK e AST no soro dos equinos intoxicados por monensina

\begin{tabular}{ccc}
\hline & CK $(\mathrm{U} / \mathrm{L})$ & AST $(\mathrm{U} / \mathrm{L})$ \\
\hline Equino 1 & 622.310 & 8.908 \\
Equino 2 & 9.241 & 1.696 \\
Equino 3 & 1.037 & 559 \\
Valores de referência* & $145-380$ & $220-600$ \\
\hline
\end{tabular}

* Radostits et al. (2007b).

Quadro 2. Resultados da quantificação da atividade das enzimas CK, LDH e AST no soro dos avestruzes intoxicados por monensina

\begin{tabular}{rccc}
\hline & CK (U/L) & LDH (U/L) & AST (U/L) \\
\hline Avestruz 1 & 7.469 .400 & 2.005 .960 & 39.625 \\
Avestruz 2 & 3.300 .750 & 748.545 & 29.400 \\
Avestruz 3 & 12657 & 4088 & 320 \\
Valores de referência* & $632-12.240$ & $644-1.080$ & $131-485 \mathrm{U} / \mathrm{l}$
\end{tabular}

* Jensen et. al. (1992).

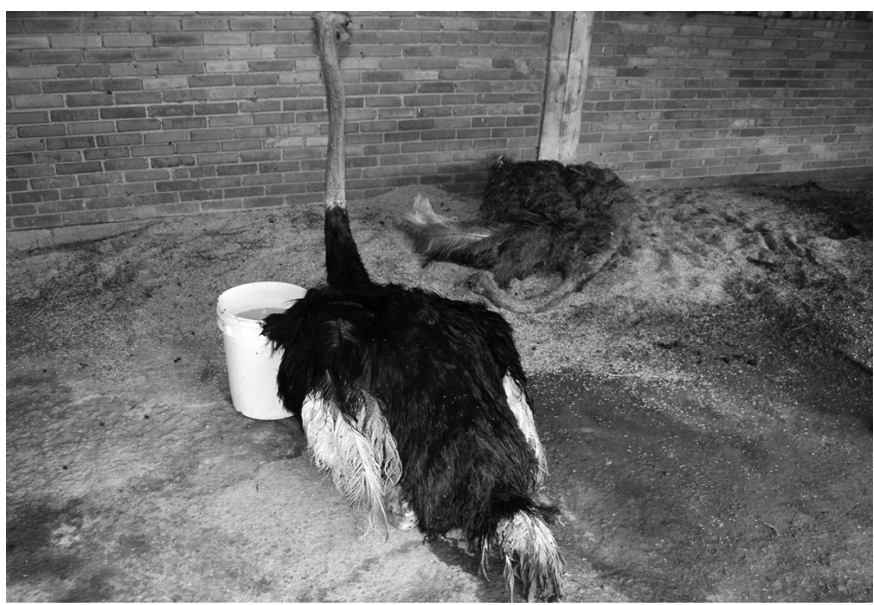

Fig.2. Avestruzes intoxicados por monensina, após 15 dias de doença clínica.

Avestruz 3 estava clinicamente normal. Os Avestruzes 1 e 2 permaneceram em decúbito permanente, com diarreia e intensa perda de condição corporal (Fig.2). 0 Avestruz 1 morreu 15 dias após o início dos sinais clínicos e o Avestruz 2, 30 dias após.

Os achados de necropsia dos Equinos 1 e 2 foram similares e caracterizaram-se por miocárdio com palidez multifocal, hemorragias no endocárdio e epicárdio, principalmente, ao redor dos vasos coronarianos (Fig.3). Hidropericárdio moderado foi observado no Equino 2. A musculatura esquelética apresentava áreas branco-amareladas localmente extensas bilaterais e edema entre as fáscias musculares (Fig.4). Essas alterações foram mais intensas nos membros pélvicos. Os pulmões estavam hipocrepitantes, vermelho-escuros e com grande quantidade de líquido espumoso no interior de brônquios.

À necropsia, ambos os avestruzes apresentavam má condição corporal e escaras de decúbito. No Avestruz 1, detectaram-se músculos esqueléticos difusamente pálidos com múltiplos pequenos pontos brancos (Fig.5), além de nódulos $(0,3-1,0 \mathrm{~cm})$ multifocais, firmes e esbranquiçados nos pulmões e sacos aéreos. 0 Avestruz 2 apresentou áreas pálidas multifocais na musculatura esquelética e ocasionais pontos brancos pequenos dispersos na musculatura

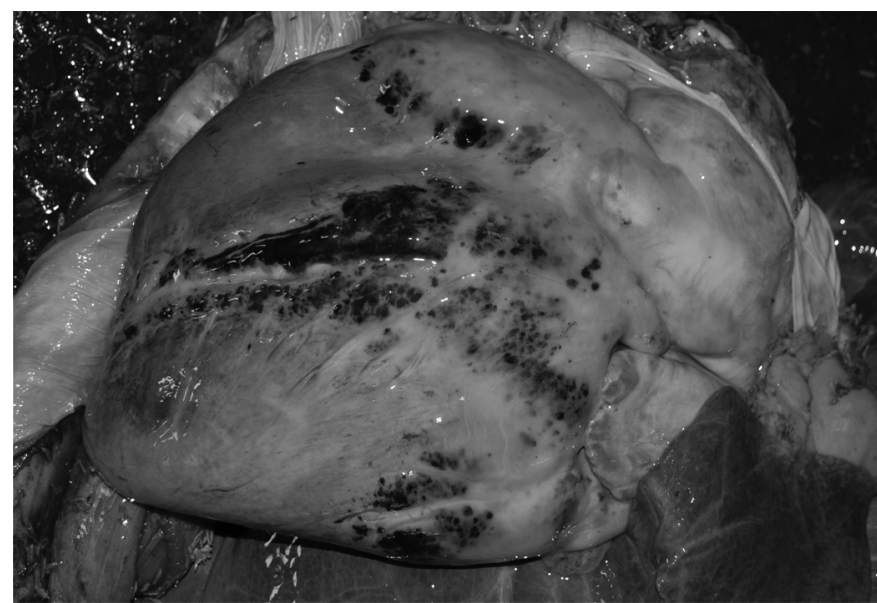

Fig.3. Coração com palidez multifocal, hemorragia no epicárdio, principalmente, ao redor dos vasos coronarianos, de equino intoxicado por monensina.

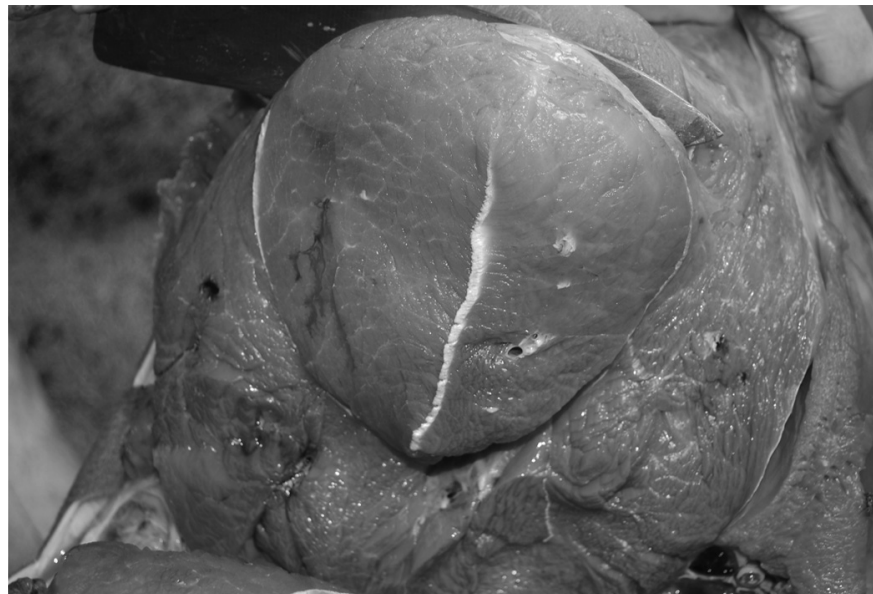

Fig.4. Equino intoxicado por monensina. Músculo quadríceps femoral com áreas branco-amareladas.

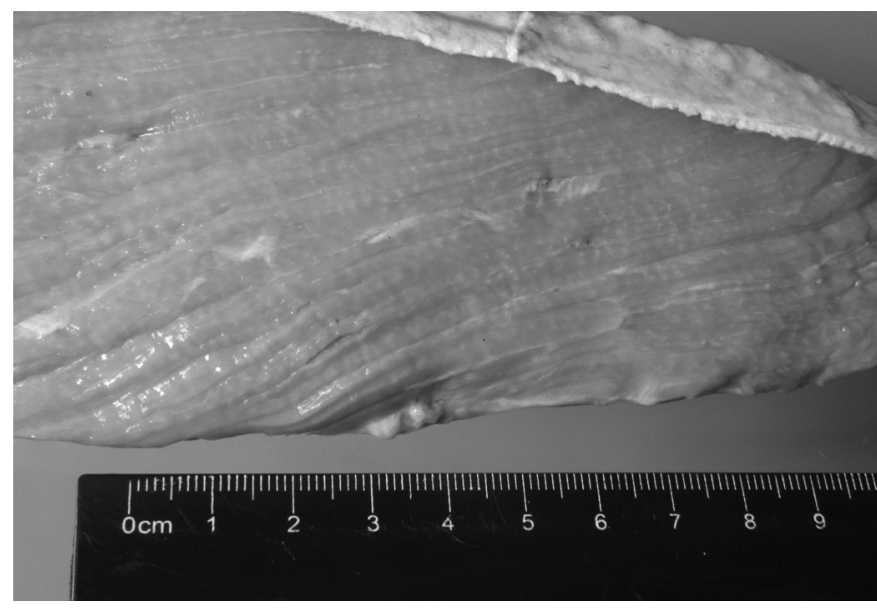

Fig.5. Músculo gastrocnêmio lateral pálido com múltiplos pequenos pontos brancos, de avestruz intoxicado por monensina. 
dos membros pélvicos, além de áreas hemorrágicas multifocais e grande quantidade de material amarelado fibrinoso nos sacos aéreos, cuja análise microbiológica identificou Escherichia coli.

Histologicamente, os músculos esqueléticos dos equinos apresentavam necrose segmentar, multifocal a coa- lescente, caracterizada por fibras tumefeitas, sarcoplasma mais eosinofílico, perda de estriações, o que conferia aspecto homogêneo ao citoplasma e, ocasionalmente, núcleos picnóticos ou ausentes (necrose hialina). Em outras áreas, havia segmentos de fibras com fragmentação do sarcoplasma que formavam aglomerados de detritos
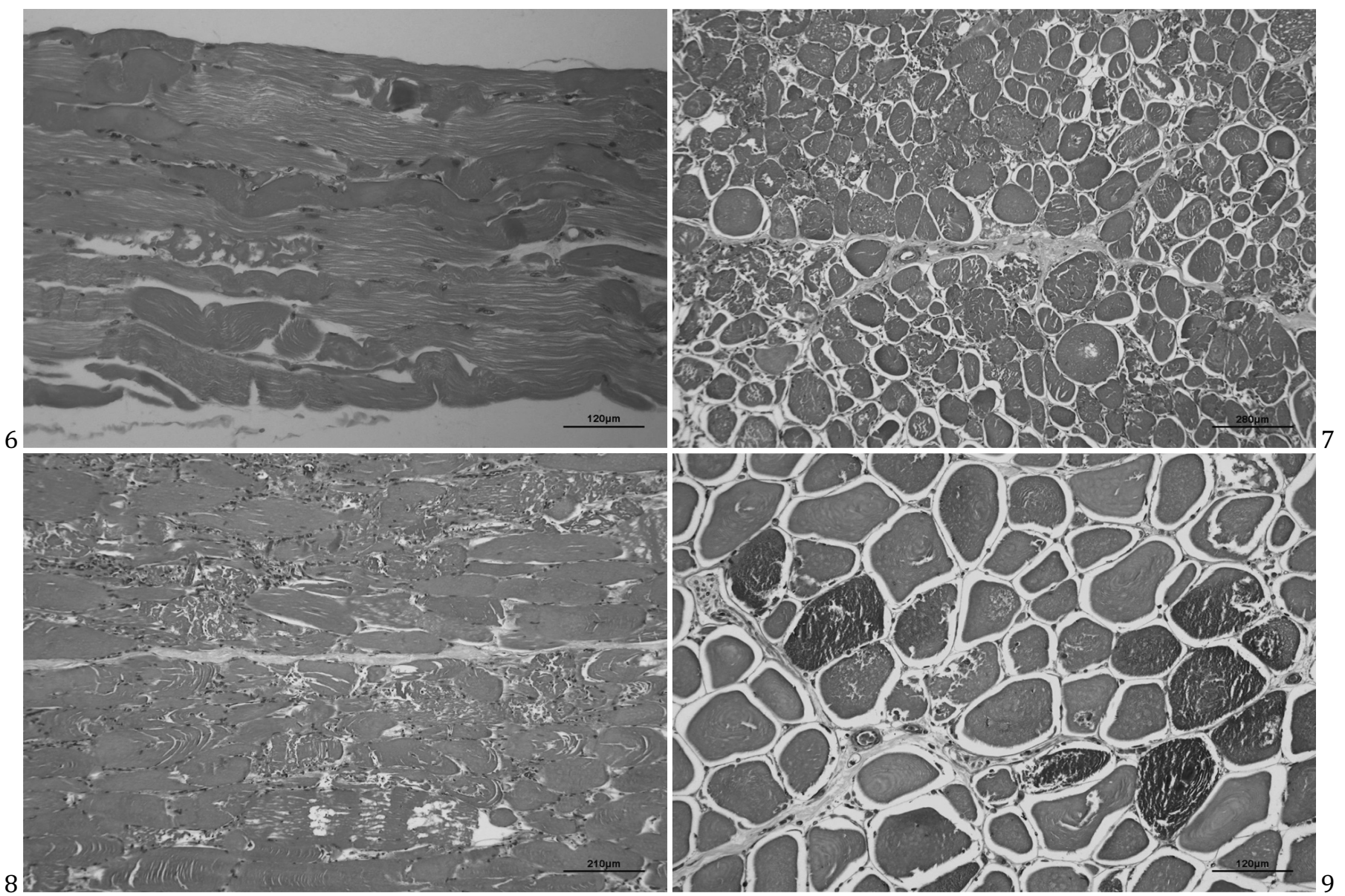

8
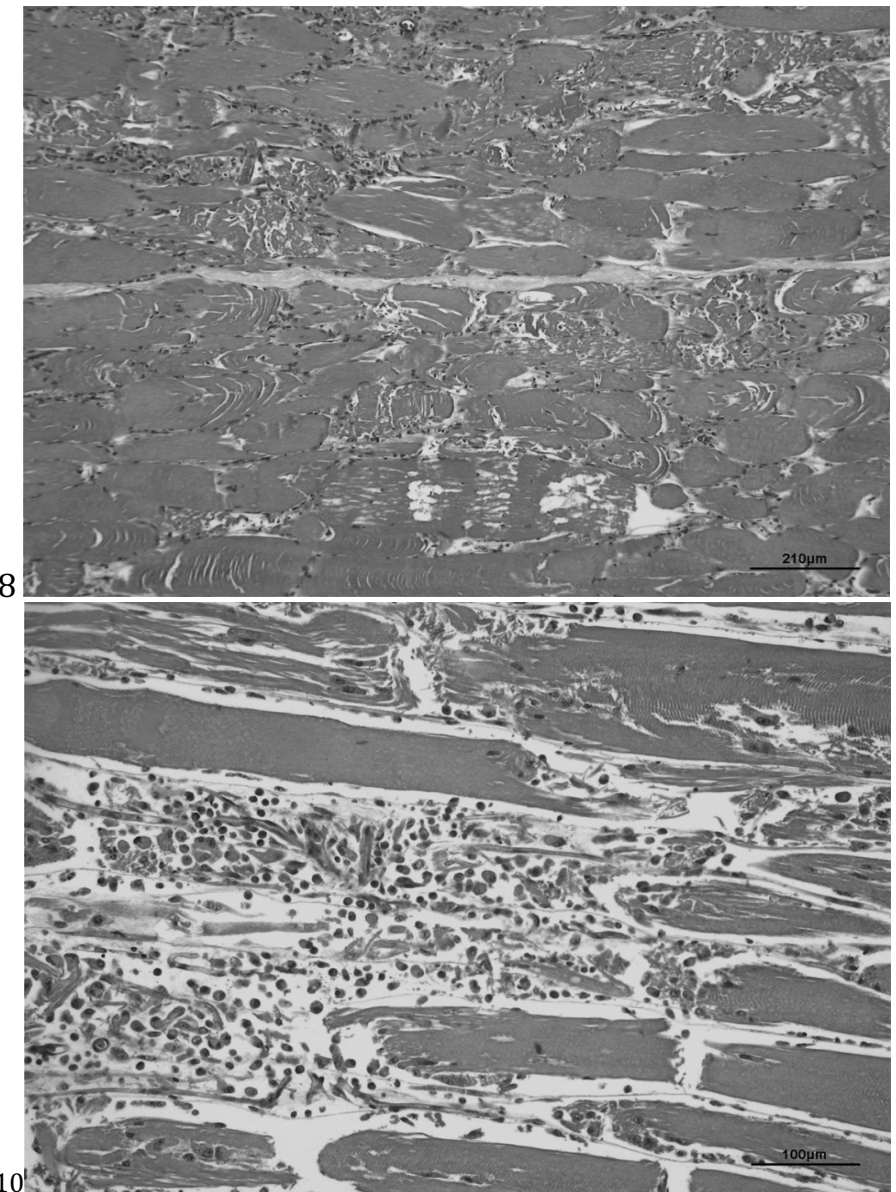

Fig.6. Musculatura esquelética com necrose hialina e flocular, de eqüino intoxicado por monensina. HE.

Fig.8. Músculo esquelético com necrose hialina e flocular (corte transversal), de avestruz intoxicado por monensina. HE.

Fig.10. Músculo esquelético com infiltrado inflamatório constituído predominantemente por macrófagos, de avestruz intoxicado por monensina. HE.

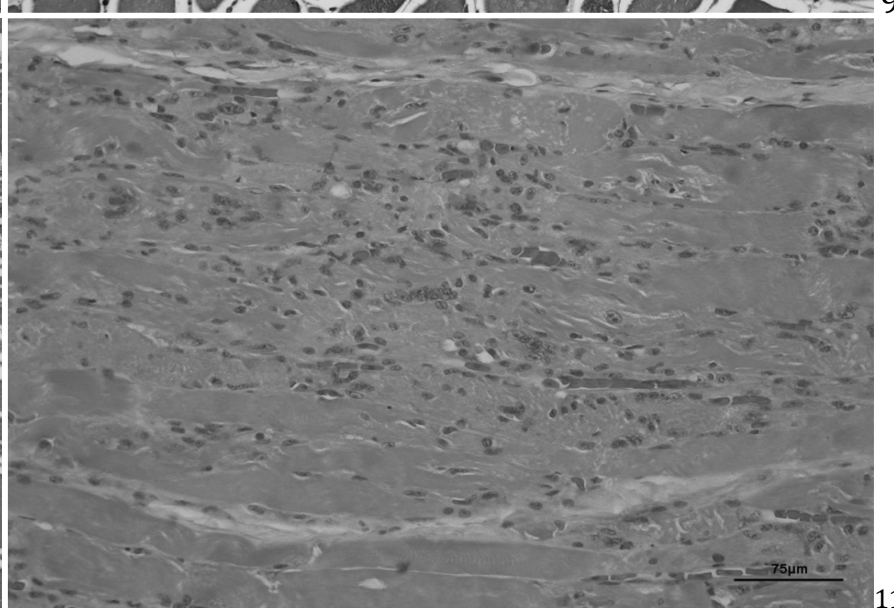

Fig.7. Músculo esquelético com necrose hialina e flocular (corte longitudinal), de avestruz intoxicado por monensina.. HE.

Fig.9. Mineralização multifocal de fibras musculares esqueléticas, em avestruz intoxicado por monensina. HE.

Fig.11. Fibras musculares esqueléticas em processo de regeneração, em avestruz intoxicado por monensina. HE. 
eosinofílicos irregulares, com aspecto de flocos (necrose flocular). Ruptura e hipercontração segmentar de fibras também foram observadas (Fig.6). No exame histológico do coração dos equinos, foram observados grupos de cardiomiócitos ou células individuais com pronunciada eosinofilia citoplasmática e perda das estriações, além de ocasionais núcleos picnóticos. Nos pulmões, havia congestão e edema difusos acentuados. Nos avestruzes, a histologia revelou necrose hialina e flocular (Fig.7 e 8), fibras musculares esqueléticas multifocais com material basofílico granular a cristalino (mineralização) (Fig.9) e infiltrado de macrófagos com citoplasma abundante e eosinofílico em fibras com necrose segmentar (Fig.10), em associação com ocasionais células gigantes multinucleadas e invasão celular, além de regeneração de miofibras (basofílicas, estreitas, sem estriações e com os núcleos centralizados) (Fig.11). Ocasionais focos de fibrose intersticial foram evidenciados pela coloração TM (Fig.12). Em fibras com necrose hialina, identificou-se vacuolização citoplasmática. A distribuição e a intensidade dos diferentes tipos de alterações histológicas na musculatura esquelética dos

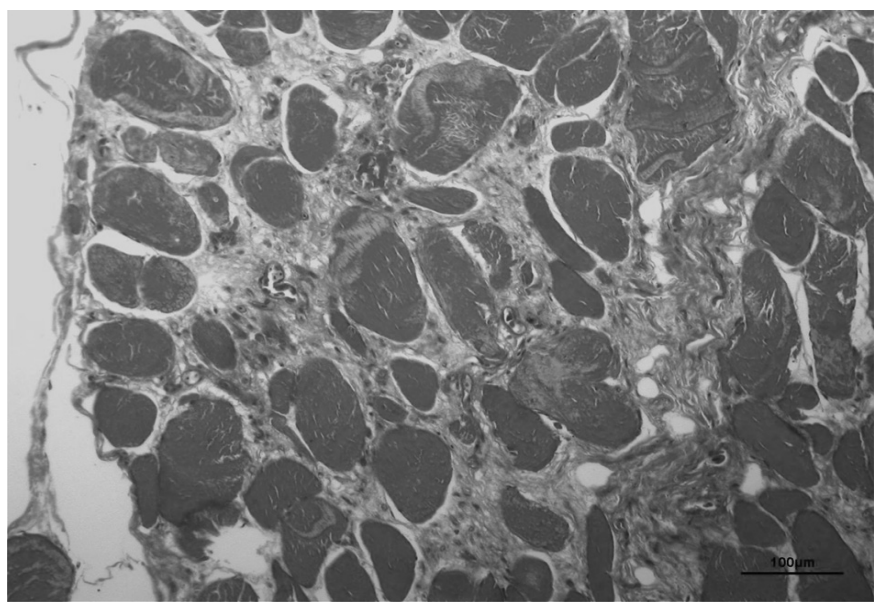

Fig.12. Musculatura esquelética com fibrose intersticial, em avestruz intoxicado por monensina. Coloração Tricrômico de Masson.

Quadro 3. Intensidade e distribuição das lesões em músculos esqueléticos no Avestruz 1 intoxicado por monensina

\begin{tabular}{lcccccc}
\hline Músculo & $\mathrm{NH}^{\mathrm{a}}$ & $\mathrm{NF}$ & $\mathrm{IMS}$ & $\mathrm{R}$ & $\mathrm{F}$ & $\mathrm{M}$ \\
\hline Iliotibial cranial & $-\mathrm{b}$ & ++ & ++ & ++ & - & ++ \\
Femorotibial médio & + & ++ & + & ++ & - & ++ \\
Tibial cranial & + & ++ & + & + & - & - \\
Obturador medial & ++ & ++ & + & + & - & + \\
Gastrocnêmio lateral & + & ++ & + & + & - & +++ \\
Bíceps braquial & + & + & + & + & - & - \\
Parede abdominal & + & +++ & + & + & - & - \\
Longo Ventral do pescoço & + & + & + & +++ & - & - \\
Gastrocnêmio medial & + & ++ & ++ & ++ & - & + \\
Tríceps escapular & + & ++ & + & ++ & - & - \\
Fibular longo & - & + & +++ & + & - & - \\
Pectíneo & + & ++ & - & + & - & ++ \\
Iliotibial lateral & + & ++ & ++ & + & - & + \\
Pubisquiofemoral & + & ++ & - & - & - & - \\
Intercostal & + & - & - & - & - & -
\end{tabular}

$\overline{\mathrm{a}} \mathrm{NH}=$ necrose hialina, $\mathrm{NF}=$ necrose flocular, IMS = infiltrado de macrófagos e células satélites, $\mathrm{R}=$ regeneração, $\mathrm{F}=$ fibrose, $\mathrm{M}=$ mineralização.

b + Lesão leve, ++ moderada, +++ acentuada, - ausente.
Quadro 4. Intensidade e distribuição das lesões em músculos esqueléticos no Avestruz 2 intoxicado por monensina

\begin{tabular}{lcccccc}
\hline Músculo & $\mathrm{NH}^{\mathrm{a}}$ & $\mathrm{NF}$ & $\mathrm{IMS}$ & $\mathrm{R}$ & $\mathrm{F}$ & $\mathrm{M}$ \\
\hline Iliotibial cranial & $-\mathrm{b}$ & + & + & + & ++ & - \\
Femorotibial médio & - & + & + & ++ & + & - \\
Tibial cranial & - & + & + & + & ++ & - \\
Obturador medial & - & - & - & - & + & - \\
Gastrocnêmio lateral & - & ++ & ++ & ++ & + & + \\
Bíceps braquial & + & + & - & + & ++ & - \\
Parede abdominal & ++ & ++ & + & ++ & + & + \\
Longo Ventral do pescoço & - & - & - & + & - & - \\
Gastrocnêmio medial & + & ++ & + & + & +++ & + \\
Tríceps escapular & - & + & - & ++ & - & - \\
Fibular longo & + & + & ++ & ++ & + & ++ \\
Pectíneo & - & + & - & + & - & - \\
Iliotibial lateral & - & ++ & + & + & - & - \\
Pubisquiofemoral & - & + & - & + & - & - \\
Intercostal & - & + & - & - & - & - \\
\hline
\end{tabular}

${ }^{\mathrm{a}} \mathrm{NH}=$ necrose hialina, $\mathrm{NF}=$ necrose flocular, IMS = infiltrado de macrófagos e células satélites, $\mathrm{R}=$ regeneração, $\mathrm{F}=$ fibrose, $\mathrm{M}=$ mineralização. b + Lesão leve, ++ moderada, +++ acentuada, - ausente.

Avestruzes 1 e 2 são apresentadas nos Quadros 3 e 4, respectivamente. Nos pulmões e no saco aéreo do Avestruz 1, observou-se infiltrado histiocitário multifocal associado com áreas centrais de necrose e imagens negativas de hifas, as quais, através da coloração PMG, demonstraram septos e ramificações em ângulo agudo e com paredes paralelas, características morfológicas compatíveis com $A s$ pergillus sp. Nos sacos aéreos do Avestruz 2, havia intenso infiltrado de heterófilos, com deposição de fibrina e estruturas granulares basofílicas compatíveis com colônias bacterianas. Não foram identificadas lesões cardíacas nos avestruzes.

\section{DISCUSSÃO}

Esse diagnóstico de intoxicação por monensina foi suposto com base nos achados epidemiológicos, clínicos, bioquímicos e patológicos. Os níveis de monensina detectados no alimento ingerido pelos animais confirmaram o diagnóstico. A fonte de intoxicação dos animais nesse surto foi a ração originalmente formulada para bovinos. 0 uso de ração para espécies não-alvo é se não a mais frequente, uma das principais causas da intoxicação por antibióticos ionóforos. Outro fator que contribuiu para a intoxicação foi a alta concentração de monensina na ração $(177 \mathrm{ppm})$, valor elevado mesmo para bovinos, cuja recomendação (como promotor de crescimento) é de 16,5-33ppm (Radostits et al. 2007b). Nesse surto, somente equinos e avestruzes foram afetados, enquanto suínos e ovelhas que também consumiram a ração não apresentaram sinais clínicos. A espécie equina é considerada a mais suscetível à intoxicação por AI. A dose tóxica de monensina para equinos é $2-3 \mathrm{mg} / \mathrm{kg}$ (Matsuoka 1976). Em contrapartida, as aves são consideradas as mais resistentes à intoxicação por $\mathrm{AI}$, com doses tóxicas em torno de 200ppm em galinhas (Hanrahan et al. 1981). Todavia, entre as espécies aviárias já estudadas, os avestruzes são as mais sensíveis aos AIs, inclusive surtos de intoxicação por monensina nessa espécie foram causados por consumo de ração com 27 e 49ppm (Gregory et al. 1992, Baird et al. 1997), níveis inferiores aos observados nesse caso. 
A lesão histológica observada na musculatura esquelética dos avestruzes foi classificada como necrose segmentar polifásica, por apresentar tanto lesões necróticas, quanto regenerativas. Focos de mineralização de miofibras são alterações incomuns em descrições de intoxicações por AIs em animais (Nogueira et al. 2009); no entanto, tal alteração tem sido identificada na doença em avestruzes (Gregory et al. 1992, Baird et al. 1997). Nos presentes casos, possivelmente, essa alteração, como os focos de fibrose (em maior quantidade no Avestruz 2), estejam associados com curso clínico prolongado da doença. $\mathrm{O}$ aumento da atividade plasmática das enzimas CK, AST e LDH observados nos animais desse estudo são achados típicos em miopatias (Radostits et al. 2007a) e auxiliam o diagnóstico clínico. Em comparação com os casos fatais, valores inferiores dessas enzimas foram observados no Avestruz 3 e no Equino 3, que não morreram, o que demonstra correlação entre intensidade de lesão e valores dessas enzimas.

A morte nos equinos intoxicados por AIs é geralmente atribuída à insuficiência cardíaca associada à cardiomiopatia degenerativa (Novilla 1992); entretanto, em alguns casos não são observadas lesões macro e microscópicas no coração. No presente caso, a lesão histológica no coração dos equinos afetados era sutil e, possivelmente, a morte desses equinos foi favorecida por insuficiência respiratória causada por miopatia degenerativa dos músculos intercostais e diafragmáticos, alterações observadas em outro estudo (Bezerra et al. 2000). Já a morte dos avestruzes nesse trabalho foi atribuída a infecções respiratórias, uma fúngica e outra bacteriana. A associação de longa permanência em decúbito com baixo consumo alimentar e estresse, possivelmente, favoreceu as infecções oportunistas no trato respiratório dessas aves.

0 diagnóstico diferencial da intoxicação por AI em equinos deve incluir, principalmente, doenças que cursam com lesões musculares como rabdomiólise de esforço (Radostits et al. 2007a). Os achados epidemiológicos e a identificação do AI na ração são fatores essenciais na conclusão do diagnóstico (Novilla 1992). Intoxicação por Senna occidentalis em equinos cursa com lesões musculares mais discretas que as da intoxicação por AI e o parênquima hepático também é afetado (Irigoyen et al. 1991). Sinais iniciais de cólica, conforme observados no Equino 2, são descritos em equinos intoxicados por AI; no entanto, geralmente, são seguidos por distúrbios locomotores, o que difere de outras causas de cólica (Bezerra et al. 2000). Sudorese é um sinal clínico frequente em equinos intoxicados por AI (Rollinson et al. 1987, Bezerra et al. 2000). Excitação e dor podem causar sudorese em equinos, pois suas glândulas sudoríparas são inervadas por nervos simpáticos, cujo neurotransmissor é adrenalina (Bezerra et al. 2000). Os diagnósticos diferenciais de intoxicação por monensina em avestruzes incluem miopatia nutricional associada à deficiência de vitamina $\mathrm{E}$ e selênio que ocorre principalmente em animais jovens (Aganga et al. 2003), miopatia de captura (Jensen et al.
1992) que inclui história de exercício rigoroso prévio e miopatia degenerativa associada com decúbito prolongado e estase gástrica (Shakespeare 1995). No presente relato, histórico e sinais clínicos indicam que a lesão muscular precedeu o decúbito e não foi resultado dele. Os dados apresentados confirmam a alta sensibilidade da espécie equina à intoxicação por $\mathrm{AI}$ e alertam que cuidados devem ser observados na alimentação de avestruzes com rações que contêm AI.

Agradecimentos.- Ao Conselho Nacional de Desenvolvimento Científico e Tecnológico (CNPq) e à Coordenação de Aperfeiçoamento de Pessoal de Nível Superior (CAPES) pela concessão de bolsas. Ao proprietário da propriedade Rafael Cruz.

\section{REFERÊNCIAS}

Aganga A.A., Aganga A.O. \& Omphile U.J. 2003. Ostrich feeding and nutrition. Pak. J. Nutr. 2(2):60-67.

Baird G.J., Caldow G.L., Peek I.S. \& Grant D.A. 1997. Monensin toxicity in a flock of ostriches. Vet. Rec. 140(24):624-626.

Barros C.S.L. 2007. Intoxicação por antibióticos ionóforos, p.45-50. In: Riet-Correa F., Schild A.L., Lemos R.A.A. \& Borges J.R. (Eds), Doenças de Ruminantes e Equinos. Varela, São Paulo.

Bezerra P.S., Driemeier D., Loretti A.P., Riet-Correa F., Kamphues J. \& Barros C.S.L. 1999. Monensin poisoning in Brazilian horses. Vet. Human Toxicol. 41(6):383-385.

Bezerra P.S., Ilha M.R.S., Langohr I.M. \& Barros C.S.L. 2000. Intoxicação experimental por monensina em equinos. Pesq. Vet. Bras. 20(3):102108.

Dedoussi A., Roubies N. \& Tserveni-Goussi A. 2007. Monensin toxicity in ostriches on a farm in northern Greece. Vet. Rec. 161(18):628 629.

França T.N., Nogueira V.A., Yamasaki E.M., Caldas S.A., Tokarnia C.H. \& Peixoto P.V. 2009. Intoxicação acidental por monensina em ovinos no Estado do Rio de Janeiro. Pesq. Vet. Bras. 29(9):743-746.

Gregory D.G., Edwards W.C. \& Stair E.L. 1992. A case of monensin poisoning in ostriches. Vet. Hum. Toxicol. 34(3):247.

Hanrahan L.A., Corrier D.E. \& Nagi S.A. 1981. Monensin toxicosis in broiler chickens. Vet. Pathol. 18(5):665-671.

Irigoyen L.F., Graça D.L. \& Barros C.S.L. 1991. Intoxicação por Cassia occidentalis (Leg. Caes.) em equinos. Pesq. Vet. Bras. 1(1/2):35-44.

Jensen J.M., Johnson J.H. \& Weiner S.T. 1992. Husbandry and Medical Management of Ostriches, Emus and Rheas. Wildlife and Exotic Animal Teleconsultants College Station, p.87.

Matsuoka T. 1976. Evaluation of monensin toxicity in the horse. J. Am. Vet. Med. Assoc. 169(10):1098-1100.

Miskimins D.W. \& Neiger R.D. 1996. Monensin toxicosis in swine. J. Vet. Diagn. Invest. 8(3):396-397.

Nogueira V.A., França T.N. \& Peixoto P.V. 2009. Intoxicação por antibióticos ionóforos em animais. Pesq. Vet. Bras. 29(3):191-197.

Novilla M.N. 1992. The veterinary importance of the toxic syndrome induced by ionophores. Vet. Hum. Toxicol. 34(1):66-70.

Radostits O.M., Gay C.C., Hinchcliff K.W. \& Constable P.D. 2007a. Diseases associated with inorganic and farm chemicals, p.1798-1850. In: Ibid (Eds), Veterinary Medicine. $10^{\text {th }}$ ed. Saunders Elsevier, Oxford.

Radostits O.M., Gay C.C., Hinchcliff K.W. \& Constable P.D. 2007b. Appendix 2, p.2048. In: Ibid. (Eds), Veterinary Medicine. $10^{\text {th }}$ ed. Saunders Elsevier, Oxford. 
Rollinson J., Taylor F.G.R. \& Chesney J. 1987. Salinomycin poisoning in horses. Vet. Rec. 121(6):126-128

Rozza D.B., Vervuert I., Kamphues J., Cruz C.E.F. \& Driemeier D. 2006. Monensin toxicosis in water buffaloes (Bubalus bubalis). J. Vet. Diagn. Invest. 18(5):494-496.

Schweitzer D., Kimberling G., Spraker T. \& Sterner E.E. 1984. Accidental monensin sodium intoxication of feedlot cattle. J. Am. Vet. Med. Assoc. 184(10):1273-1276.

Shakespeare A.S. 1995. Recumbency in ostriches. Comp. Cont. Educ. Pract. Vet. 17:1440-1447.

Wilson J.S. 1980. Toxic myopathy in a dog associated with the presence of monensin in dry food. Can. Vet. J. 21(1):30-31. 